\title{
Following Up on Interdisciplinary Encounters: Benefits for Early Career Researchers
}

\author{
HELEN B R I D LE \\ Institute of Biological Chemistry, Biophysics and Bioengineering, Heriot-Watt \\ University, Riccarton Campus, Edinburgh, EH14 4AS, Scotland, UK. \\ Email: h.1.bridle@hw.ac.uk
}

\begin{abstract}
Interdisciplinarity is often quoted as a means to solve the complex social challenges faced by humanity, and the future of research is thus seen as increasingly interdisciplinary. However, there are risks and challenges to embarking on interdisciplinary research, particularly for early-career researchers. Encounters - bringing together early-career researchers to cultivate their interdisciplinary skills or to develop new projects - have been proposed and trialled as a means to boost interdisciplinarity amongst early-career researchers and equip them with the necessary skills for successful project delivery. However, little follow-up evaluation has been undertaken, especially considering career impacts several years after encounter participation. This article focuses on two encounter types and evaluates the level of interdisciplinary interactions obtained and the benefits experienced by participants. In conclusion, encounters are found to be highly successful, resulting in many projects and skills/career development. As such, further funding should be allocated to this type of event.
\end{abstract}

\section{Introduction}

Interdisciplinary research is often seen as essential to providing solutions to complex societal problems ${ }^{1-3}$ and it has been predicted that the future of research is increasingly interdisciplinary. ${ }^{4}$ While there are benefits of interdisciplinarity, there are also well recognized challenges and risks, ${ }^{5}$ e.g. difficulties in communication, longer timescales to successful outputs, lack of peer support and feeling valued. ${ }^{1,3,6-9}$

Early-career researchers are often motivated to participate in interdisciplinary projects due to the chance to address societal problems (e.g. personal motivation by the problem/topic and the feeling that the work is important to society) and the enjoyment of specific interdisciplinary collaborations. ${ }^{8}$ However, due to academic and reward systems often being aligned with disciplines, some of the risks of high time 
Table 1. Overview of interdisciplinary encounter types: adapted from a presentation by Phil Ward entitled 'Supporting Interdisciplinarity' given at a British Academy Event in 2015. ${ }^{10}$

\begin{tabular}{|c|c|c|c|}
\hline Encounter type & Details & Advantages & Disadvantages \\
\hline Laissez-faire & $\begin{array}{l}\text { Naturally occurring, e.g. } \\
\text { conferences, coffee } \\
\text { shops, meetings }\end{array}$ & $\begin{array}{l}\text { Links tend to be more } \\
\text { enduring. } \\
\text { No external effort }\end{array}$ & $\begin{array}{l}\text { Interdisciplinarity? } \\
\text { Haphazard. } \\
\text { Not in priority areas }\end{array}$ \\
\hline Seminar series & $\begin{array}{l}\text { E.g. University of Kent } \\
\text { lunchtime seminars. } \\
\text { Lunch and talk/ } \\
\text { discussion. } \\
20-40 \text { people }\end{array}$ & $\begin{array}{l}\text { Broad appeal. } \\
\text { Social element }\end{array}$ & $\begin{array}{l}\text { No substantial } \\
\text { collaboration arose. } \\
\text { Increasingly similar } \\
\text { group. } \\
\text { Lot of effort }\end{array}$ \\
\hline $\begin{array}{l}\text { Interdisciplinary } \\
\text { networks }\end{array}$ & $\begin{array}{l}\text { University ECR } \\
\text { networks, Young } \\
\text { Academies }\end{array}$ & $\begin{array}{l}\text { Geographical } \\
\text { proximity }\end{array}$ & $\begin{array}{l}\text { Haphazard. } \\
\text { Aims? }\end{array}$ \\
\hline $\begin{array}{l}\text { Building teams } \\
\text { for specific calls }\end{array}$ & $\begin{array}{l}\text { Sandpits, university } \\
\text { actions }\end{array}$ & $\begin{array}{l}\text { Focus by theme. } \\
\text { Commitment from } \\
\text { funder }\end{array}$ & $\begin{array}{l}\text { Need to be organized } \\
\text { (ahead of } \\
\text { announcements). } \\
\text { Time consuming. } \\
\text { Good leadership } \\
\text { essential }\end{array}$ \\
\hline $\begin{array}{l}\text { Interdisciplinary } \\
\text { workshops/ } \\
\text { conferences }\end{array}$ & $\begin{array}{l}\text { E.g. European Science } \\
\text { Foundation, Junior } \\
\text { Summit on Water or } \\
\text { Facing the Future }\end{array}$ & $\begin{array}{l}\text { Intense focus. } \\
\text { Free of distractions }\end{array}$ & $\begin{array}{l}\text { Academics too busy? } \\
\text { Selection of attendees? } \\
\text { Long-term? }\end{array}$ \\
\hline $\begin{array}{l}\text { Interdisciplinary } \\
\text { programmes }\end{array}$ & Crucible & $\begin{array}{l}\text { Intense focus. } \\
\text { Funding attached }\end{array}$ & $\begin{array}{l}\text { Academics too busy? } \\
\text { Long-term? }\end{array}$ \\
\hline
\end{tabular}

investment for initial little return limiting outputs, and lack of a disciplinary home for lectureship and funding applications are particularly problematic for early-career researchers trying to establish their careers. ${ }^{1,6,9}$

Furthermore, it may be challenging for even those highly-motivated early-career researchers to engage in interdisciplinary projects due to a lack of extensive network or publication list to leverage collaborations. ${ }^{6}$ Therefore, it has been concluded that there is an urgent need for formats to facilitate interdisciplinary interactions for early career researchers. ${ }^{1,3,6,9}$ Several of these types of encounter have been developed, focusing either on the cultivation of appropriate skills, or the direct development of interdisciplinary projects, or a combination of the two. ${ }^{1}$ An overview of encounter types, not specific to early-career researchers, is given in Table 1, adapted from a presentation by Phil Ward entitled 'Supporting Interdisciplinarity' (see https://slideplayer.com/slide/4141854/), given at a British Academy Event in 2015. ${ }^{10}$ Details, advantages and disadvantages of each approach are identified.

Specific examples of the latter two encounter types, e.g. specific workshops or programmes, targeting early-career researchers, include Facing the Future, ${ }^{6}$ Masterclasses, ${ }^{4}$ Crucible, ${ }^{1}$ the European Science Foundation (ESF) Junior Summit ${ }^{1}$ 
and Food Futures, ${ }^{11}$ as well as postgraduate training programmes. ${ }^{3,12-14}$ Previous work has investigated the components necessary for successful design and delivery of such encounters, concluding that:

- Significant diversity in background, culture and discipline is beneficial, especially to target big interdisciplinarity (e.g. collaboration between distant disciplines) although more time might be necessary for relationship building.

- Mixed career stage encounters can be extremely beneficial, as early-career researchers found that 'a valuable aspect of the summit was the opportunity to interact with senior academics' ${ }^{1}$ and 'it was particularly interesting when senior academics shared personal experiences, both positive and negative, on interdisciplinary collaboration. ${ }^{, 6}$

- Viewpoints on whether a theme is essential vary, with participants/ organizers of the ESF Junior Summit and Facing the Future considering a theme vital, ${ }^{1,15}$ whereas Crucible and Masterclasses have been run successfully without a theme. ${ }^{1,4}$

- Place is important, as collaboration levels have been linked to the rating of the physical environment, and stepping out of one's comfort zone enhances creativity. In addition, a 'new and inspiring place promotes relationship building and creativity'.1,16-18

- In terms of size, 20-40 participants is optimal, both for networking and idea generation, ${ }^{18,19}$ e.g. "small enough to feel intimate and sufficient opportunity to interact with everyone', ${ }^{1}$ and practical considerations, e.g. 'the main reason is scale. $50+$ would require larger venues, more time to organize etc. Also, since we did "turbo talks" we did not want to have a very large group. This would hinder the informal atmosphere we wanted to create'. ${ }^{15}$

Aspects of programme structure have also been considered. Typical activities include informal group discussions, seminars/lectures (by senior academics), turbo talks, speed dating, collaboration walls, informal and socializing time, breakout discussion groups and output-related activities (e.g. reports, films, seed-funding). Ensuring a communicative attitude of appreciative inquiry, e.g. listening to, being curious of, and understanding each other's perspectives and potential contributions to joint efforts, is important ${ }^{14}$ and, with especially large groups, structured and facilitated approaches become essential. A recent Facing the Future report focused on aspects of programme structure, and found that keynotes from leading academics were useful since these '.. helped to give the conference academic rigour and were highly appreciated by participants. In our view, keynotes can serve as an important bridge between the more traditional academic conference and more experimental workshops. ${ }^{6}$ Furthermore, the workshop trialled the use of 'octasynthesis' for generating interdisciplinary ideas and discussion, finding some benefits ('by exploring synergies a more positive mindset was created that helped imagine what kind of future is possible if we work together') although it was potentially not optimized for this setting since 
participants found that the method was time-consuming, exhaustive and resulted in a loss of detail as well as a failure to address practical solutions, e.g. 'it did not take us far in considering the practical implications' and that there would be a '...need to focus on a particular design problem to make outcomes more practice-oriented. ${ }^{20,21}$

Additionally, informal social time to build relationships is important, especially since other work has concluded that trust and personal/intellectual chemistry is very important. ${ }^{4,7}$ Lyall et al. noted that pre-existing relationships can be an advantage for interdisciplinary collaboration and the lack of relationship building could be why partner search facilities have had a mixed response. ${ }^{7}$ Even if encounters don't directly result in interdisciplinary projects, the relationships and network developed is useful for future potential projects.

Overall, encounters can enable early career researchers to build their research networks, expose them to new perspectives and ideas and enhance their communication skills. To maximize success, encounters should include components such as effective facilitation, a wide diversity of participants and clearly defined aims. Evaluation has shown the benefits of encounters. However, little work has evaluated the long-term impacts in terms of the number of interdisciplinary projects delivered and the impact upon the participants in terms of skills and career development.

\section{Experimental Study}

Data were gathered from two different encounters aimed at early-career researchers. The first was the UK Crucible programme (for details see Figure 1) and the second was the European Science Foundation (ESF) Junior Summit in Stresa, entitled Water: Unite and Divide (for more details see Figure 2). The encounters were selected as examples of different approaches, with Crucible more focused on development of new projects, although with a training component, and Stresa mainly focused on cultivation of early-career researchers' interdisciplinary skills.

In the UK, both Scottish and Welsh Crucibles were run, and different data were obtained for each of them. Scottish Crucible administered a questionnaire to 243 alumni (ex-participants in the programme) in November 2016, asking questions pertaining to personal and professional development, in addition to specific outputs directly attributed to participation in the Scottish Crucible. A participation rate of $25 \%$ was achieved with 61 respondents of 243 alumni. The majority of respondents (79\%) represented 12 Scottish Higher Education Institutes, with the remaining respondents being from other UK universities, research institutes, or Small- and Medium-sized Enterprises. Five respondents had moved overseas, with $82 \%$ of respondents being still based in Scotland. The Welsh Crucible website contains six case studies of participants who described their experiences of undertaking the Welsh Crucible in $2011 .^{22}$ The text of these case studies was analysed, coding the data for mention of confidence, profile raising, generation and involvement in interdisciplinary projects and further funding being obtained. These topics were selected 


\section{Scottish Crucible}

Leadership \& Development Programme for Scotland's Research Leaders of the Future
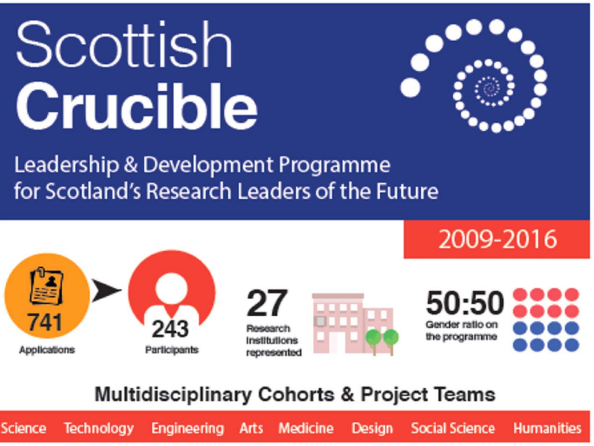

Collaboration,

Scottish Crucible is the premier

leadership and development

programme for Scotland's *Research

Leaders of the Future". It inspires highly

promising researchers to be more

ambitious, creative and innovative

while helping to forge new

interdisciplinary research

collaborations.

Inspiring excellent research and building innovative capacity

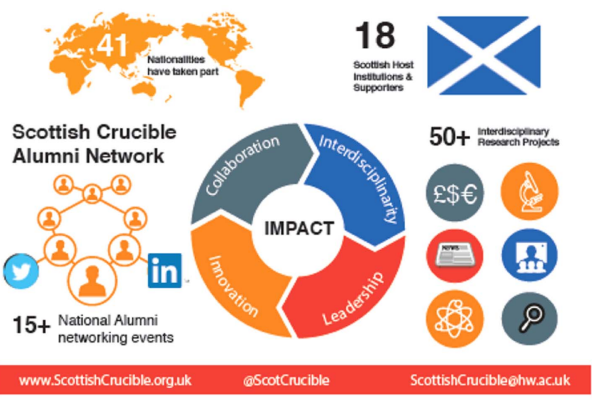

Alumni Network

rship

Participants gain a unique opportunity

to broaden their networks with senior

colleagues from different sectors,

including the Royal Society of

Edinburgh, Scottish Government

Scottish Parliament, business and

industry.

Figure 1. Overview and details of Scottish Crucible as an example of the UK Crucible programmes. Every year the programme involves three sets of 2-day workshops with an overnight stay and dinner for each one. During the final workshop, participants are encouraged to present potential interdisciplinary group projects from which a winning team is selected, although all teams, and other combinations of participants, are able to bid for a pot of seed funding, for which the interdisciplinary extent of the project is a key factor in success.

to align with the questions from the Scottish Crucible questionnaire. Additionally, relevant quotes were extracted relating to the selected topics.

With regard to the ESF Junior Summit, a questionnaire was distributed to all participants via Survey Monkey and email. Out of the 34 participants in the Stresa meeting, email contacts could be found for 32 of them (the PhD students had subsequently finished their doctorates but the majority had remained within academia and up-to-date details could be located). A participation rate of $47 \%$ was achieved with 15 respondents out of the 32 contacts. All responses were anonymous and the data were extracted directly from the Survey Monkey results analysis software.

The author of this publication participated in both Scottish Crucible and the ESF Junior Summit in 2012 but did not complete either questionnaire.

\section{Results and Discussion}

Data have been collected from participants in Crucible programmes and the European Science Foundation Junior Summit in Stresa. First, the results from the Crucible study are presented and discussed in terms of the levels of collaborative interdisciplinary projects generated and the wider benefits to participants. Second, the 

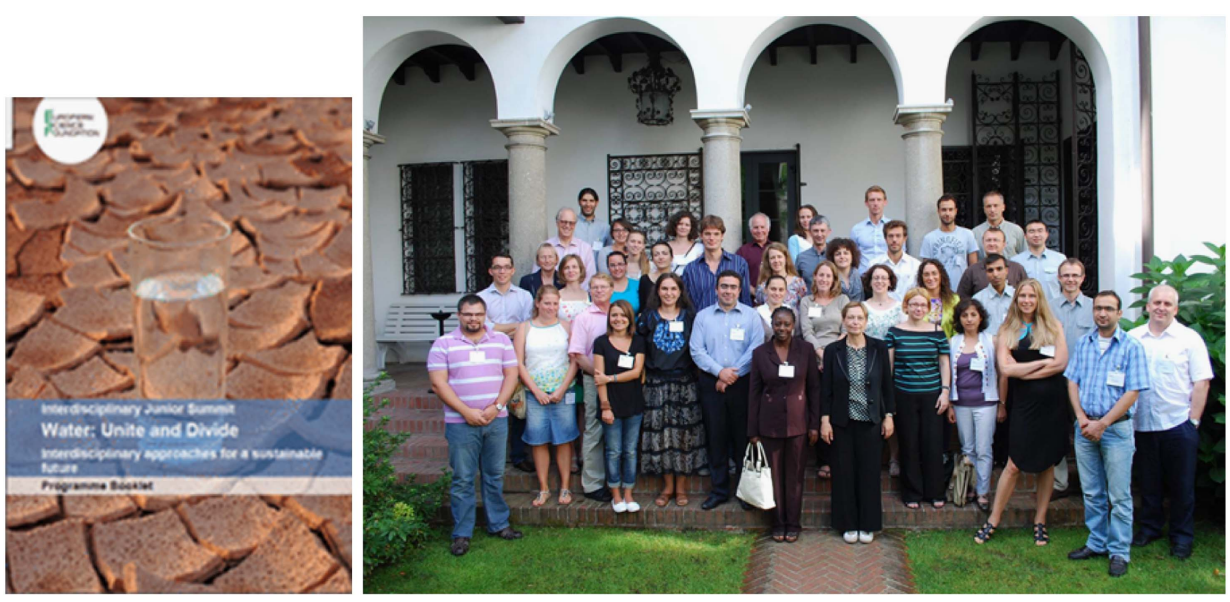

- European Science Foundation funded workshop

- 4 days in Stresa, Italy at the end of August 2012

- 34 early career researchers (selected by application) from 14 countries

- Median age 28, mostly PhD students and 25\% with more than 5 years experience

- 11 leading interdisciplinary academics from 8 countries

- Writing and video groups were formed to document the event

Figure 2. Overview and details of the ESF Junior Summit, on water.

Stresa data are given and evaluated. Finally, conclusions are drawn from both sets of results and discussed with regard to the literature.

\section{Crucible}

The aim of Crucible is to provide leadership training, focusing on creativity and innovation, as well as forging new interdisciplinary research collaborations. Seed funding is available, on a competitive basis, as a means for participants to take forward new ideas. Evaluation of the Crucible programmes was based on two sets of data, one being a questionnaire distributed to alumni of Scottish Crucible, and the other being the six case studies of Welsh Crucible participants describing their experiences. In terms of the creation of interdisciplinary projects, the Crucible programme has been relatively successful, with the majority of Scottish Crucible survey respondents reporting participation in collaborative projects (Figure 3).

Crucible is run annually and $67 \%$ of participants collaborated with those from the same cohort. Alumni activities allow for mixing between cohorts, expanding the network of participants, and $26 \%$ of respondents reported this type of collaboration, not supported by direct seed-funding after the event. This shows the interest of the respondents in interdisciplinarity and the communication skills developed during Crucible to form these new partnerships. A few Crucibilists reported collaborating with other guests at Crucible events, e.g. senior academics and policy makers, agreeing with the literature that inclusion of such people is often beneficial to encounters. 


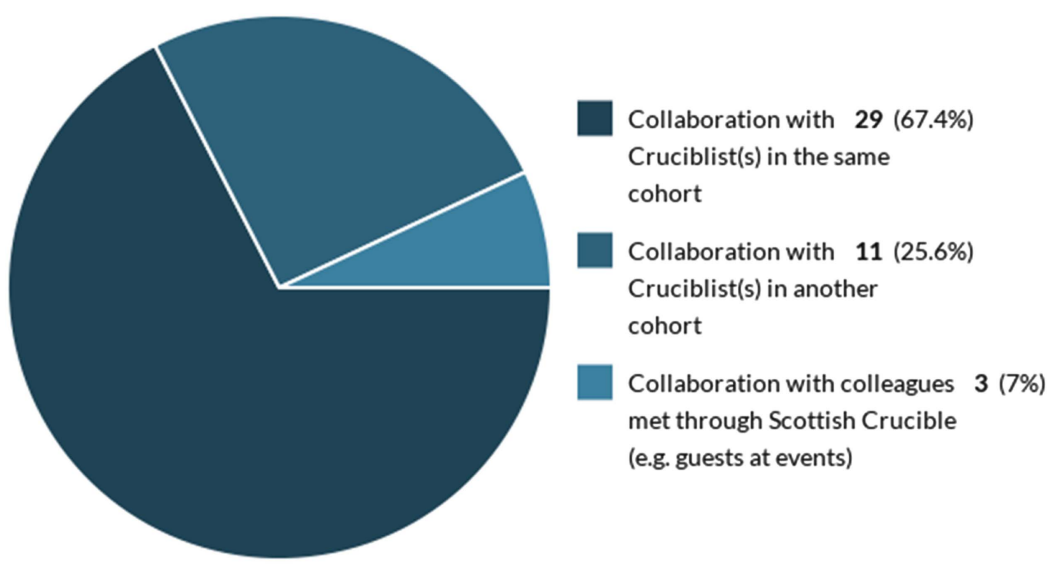

Figure 3. Responses to the question 'Have you undertaken other collaborative research activity with colleagues you met through Scottish Crucible?'

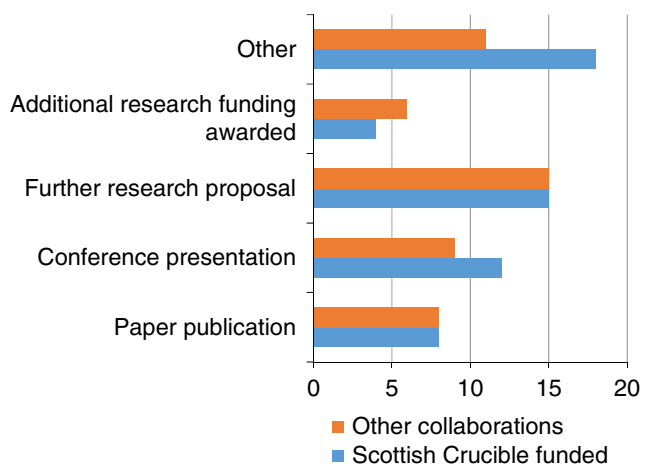

Figure 4. Responses to the question 'What outputs have arisen from Scottish Crucible-funded projects and other collaborations?'

Five out of the six Welsh Crucible participants also mentioned one or more projects that arose during or after Welsh Crucible, with 33\% of these projects achieving additional funding. Scottish Crucible collaborative interdisciplinary outputs (Figure 4) included further research proposals with a reasonable proportion being awarded funding. In addition, there were research outputs such as conference presentations or paper publications as well as creation of an app, delivery of public engagement, working with industry, student projects, working with the media, and activity for the Scottish Parliament (the latter six covered by 'other' in Figure 4). The nature of the interdisciplinarity within these collaborations has not been specified but quotes from participants suggest that, in some cases, broad interdisciplinarity was achieved, since comments related to areas the participants had never previously considered working with:

Thanks to the Crucible I've spoken in depth to researchers working in areas I'd never even considered before, which has in itself changed the way I look at my own work. 


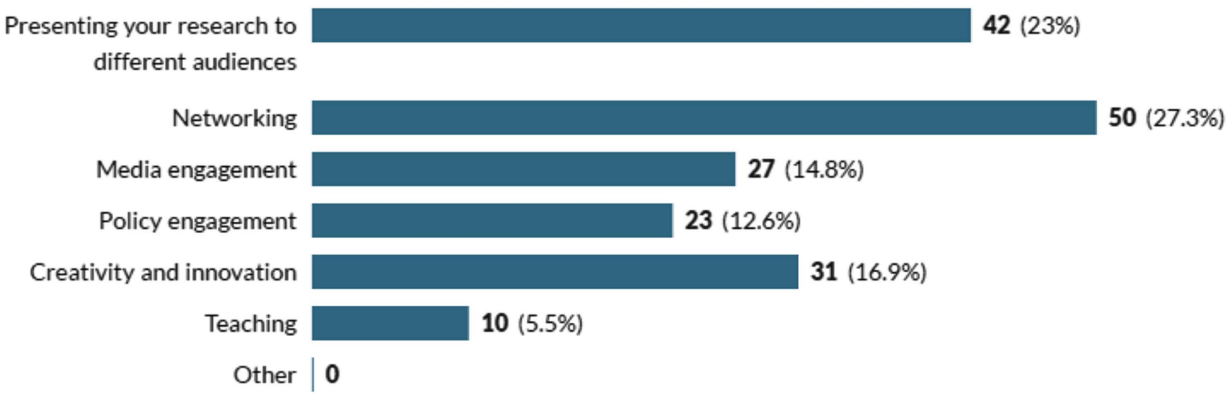

Figure 5. Responses to the question 'Has your participation in Scottish Crucible enhanced your skills in any of these areas?'

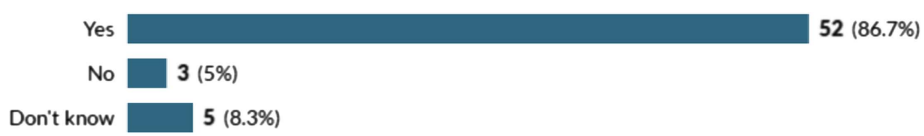

Figure 6. Responses to the question 'Has Scottish Crucible enhanced your confidence in exploring new research areas and opportunities?'

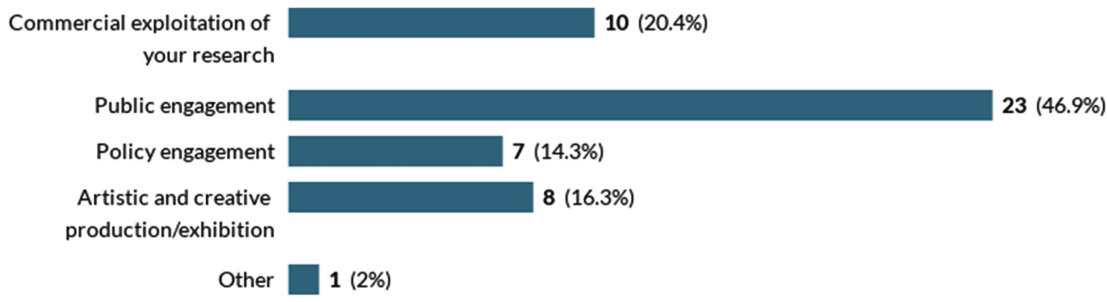

Figure 7. Responses to the question 'Have you undertaken any forms of knowledge exchange as a result of taking part in Scottish Crucible?'

...helped me to enhance my research portfolio, expand into new areas of interdisciplinary research collaboration with other academic colleagues across Wales.

[Scottish Crucible has] given me access through collaboration to areas that I hadn't before reached with my research.

Additionally, the interest of participants in interdisciplinary work seems to have been increased:

I've been more proactive at seeking out professional development opportunities and at initiating interdisciplinary collaborations.

Part of the Crucible experience is learning skills to enable interdisciplinary working (e.g. 'I learned how to lead collaborative research projects professionally and fruitfully'). However, it appears that these skills have led to a number of other benefits (Figure 5) along with participants increasing their confidence (Figure 6) and raising their profile. 


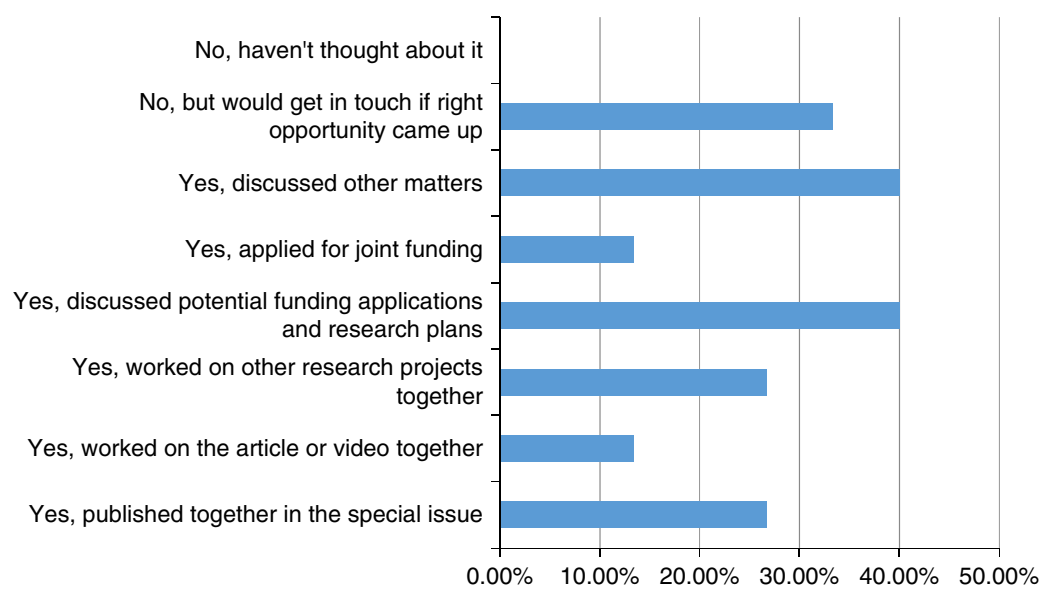

Figure 8. Responses to the question 'Are you in touch with or have worked with any of the ESF Stresa meeting participants since?'

One particular benefit, perhaps specifically linked to the improved ability to communicate effectively with different audiences, was in terms of the knowledge exchange undertaken by Scottish Crucible participants (Figure 7) including organizing 'a workshop at Scottish Government on behaviour change for health', 'providing evidence to Scottish Government and the Scottish Parliament in relation to planned or ongoing legal reform including land reform' and public engagement, e.g. 'set-up a 3D printing exhibition which was presented at Heriot-Watt Illuminations, Dunbar SciFest, Opening of the Scottish Parliament, and Midlothian Science Festival'.

With regards to confidence, comments included the following.

I've got a lot more confidence.

...given me the confidence to work with researchers in other disciplines, as well as the tools to develop these collaborations.

It was a fantastic experience which greatly increased my confidence in networking and interacting with policy makers.

Furthermore, a third of participants said that participation in Scottish Crucible had led to a raised profile, from local level (e.g. university news pages, local press), to national (e.g. radio interviews, national researcher networks). A Welsh Crucible alumni commented on how 'it encouraged me to think more carefully about my own profile.'

\section{ESF Junior Summit in Stresa}

The aim of the ESF Junior Summit on Water: Unite and Divide, held in Stresa in 2012, was to invite young researchers from across Europe to participate in discussions regarding the opportunities and challenges of interdisciplinarity. As such, this encounter could be considered a cultivation encounter focusing on the skills needed 


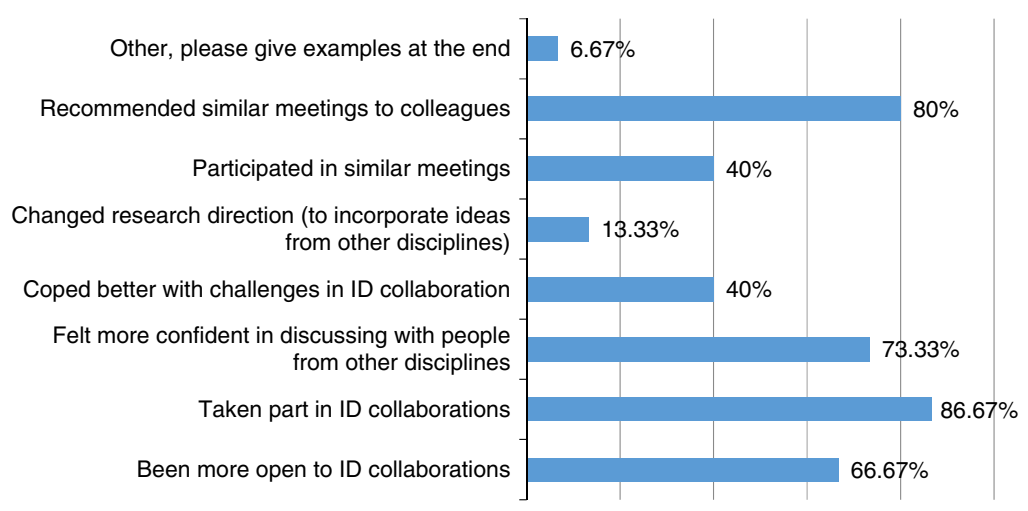

Figure 9. Responses to the question 'In terms of interdisciplinary (ID) research since Stresa have you (tick all that apply).'

for interdisciplinarity and for raising awareness of the challenges and benefits. ${ }^{1}$ However, some output-related components were included, with a writing group being tasked with producing a publication, and a video group providing an audio-visual document. Furthermore, following the workshop, a special issue in the Journal of Water Resources and Protection, comprising journal articles written by Stresa participants, was proposed and published.

The direct outputs of the workshop resulted in $27 \%$ of the respondents having worked together on special issue articles and a further 13\% having collaborated on the article or video. Furthermore, over five years later it was found that the workshop had been successful in building a research network among the early-career participants, with $40 \%$ having discussed potential funding applications and plans, with $13 \%$ having actually applied for joint funding and $27 \%$ having worked on research projects together (Figure 8). One identified challenge for early-career researchers is to access an appropriate network for engaging in interdisciplinarity ${ }^{6}$ and this type of encounter seems to have offered the opportunity to develop such a network, which has been exploited by a significant proportion of participants. Additionally, a further 33\% have not yet utilized the network but consider it a potential source of collaborators if the right opportunity occurred as well as a way to keep up-to-date with developments in different areas, by following the work of other participants:

I really enjoyed the Stresa meeting and thought that it was quite pioneering in some respects (bringing us all together; the joint publication; the video) - it is a shame that, to my knowledge, there have not been further summits of this kind (or if there have been, they have not been in subject areas to which I could contribute!). Also, while I have not directly collaborated with anyone from the group (partly because I have not worked on water in a while), I have followed the work of various people with interest.

In addition, the relationship building seems to have worked well, with $40 \%$ of participants having been in touch, discussing matters other than direct research collaborations, e.g. challenges in undertaking interdisciplinarity projects, or other matters of shared research career issues, suggesting that development of peer support is 


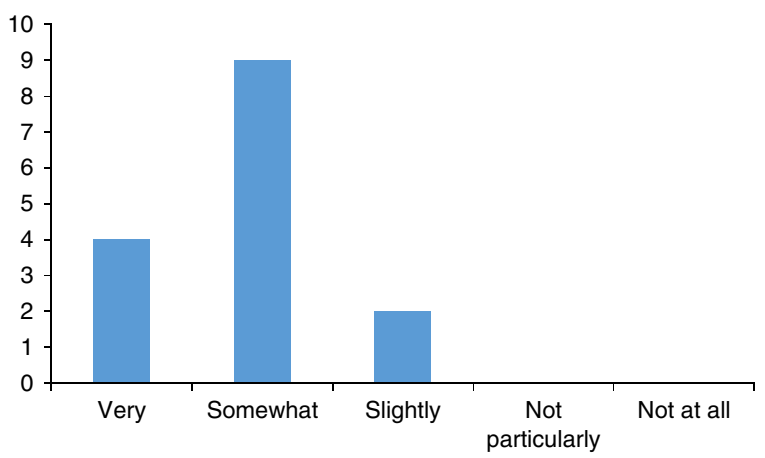

Figure 10. Responses to the question: 'To what extent do you feel the meeting has been beneficial to your career?'

one potential output of organizing encounters. This could be beneficial as the literature has shown one challenge for early-career researchers is a feeling of lack of peer support when they embark on interdisciplinary research. ${ }^{9}$

Given that one of the aims of the summit was to develop interdisciplinary skills, the questionnaire asked whether participants felt better equipped to deal with interdisciplinary research and to what extent they had engaged in interdisciplinarity (Figure 9). Eighty-seven percent of respondents had subsequently undertaken interdisciplinary collaborations, with $67 \%$ reporting a general increased level of openness towards such participation. Furthermore, $40 \%$ of respondents felt better able to cope with the challenges of interdisciplinary research, and $73 \%$ reported increased confidence in talking with people from other disciplines.

One critique of the use of encounters is that such events are extremely time-consuming, necessitating a significant commitment from participating academics, amongst many other competing demands upon their time. ${ }^{10}$ However, given that $40 \%$ of respondents had subsequently participated in similar meetings and $80 \%$ had recommended such events to colleagues, indicates that the participants found the time investment to be worthwhile. This conclusion was backed up by responses to another question, where all respondents confirmed that the meeting had been beneficial to their career, with $27 \%$ saying it was very beneficial (Figure 10).

Various career benefits to participating in the Stresa encounter were identified by respondents (Figure 11) including direct benefits such as publications and collaborative research projects, the outputs of which were beneficial to career progression. One participant commented that, following Stresa, she now has '...one of the first truly interdisciplinary Professorships in Germany'. The aims of the workshop were to broaden the perspectives of the participants in exposing them to other disciplines and for them to discuss the challenges and benefits of interdisciplinarity; $67 \%$ and $47 \%$ respectively found these factors helpful for their careers. As previously highlighted, a challenge for early career researchers in initiating interdisciplinary projects is finding appropriate collaborators, ${ }^{6}$ and $33 \%$ of respondents found the building of a network of early-career researchers in the water area very helpful, with a total of $80 \%$ finding it useful to meet other early-career researchers, and especially 


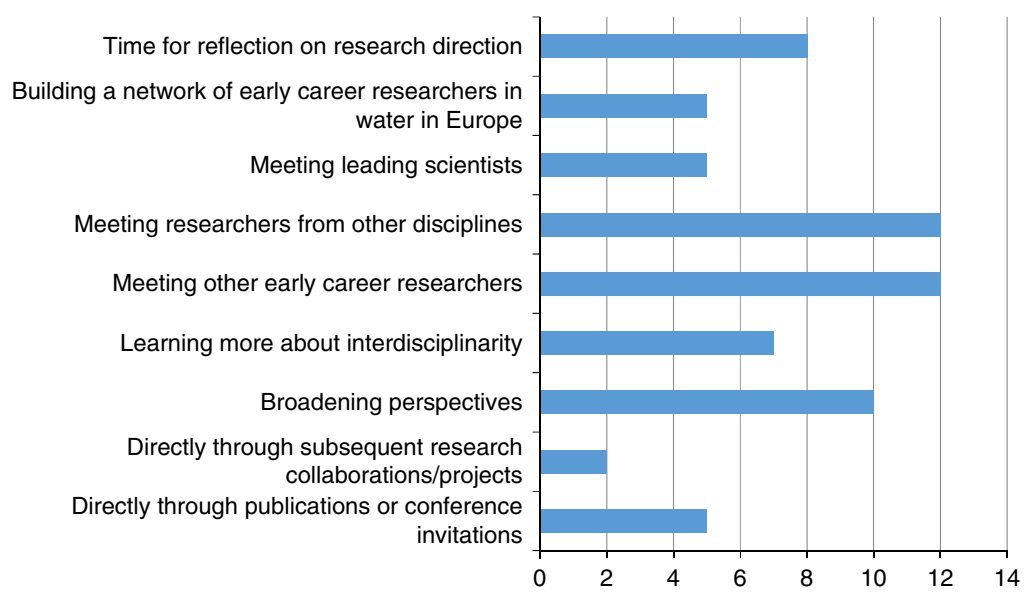

Figure 11. Responses to the question: 'Do you feel the meeting has been beneficial to your career through any of the following routes?'

those from other disciplines. Over 50\% of participants found the opportunity to step away from day-to-day work and reflect upon their research direction a useful benefit of the event, and space for reflection represents an unintended bonus of such encounters.

\section{Overall}

Both sets of data confirm that the interest of early-career researchers in interdisciplinarity is high, ${ }^{1,8}$ as evidenced by the participation in these encounters themselves and the subsequent involvement in interdisciplinary projects. A total of $67 \%$ of Crucibilists had collaborated with fellow members of their annual cohort, with $26 \%$ having collaborated across cohorts, and up to $40 \%$ of Stresa participants having either applied for joint funding, worked on interdisciplinary projects or discussed potential plans. The higher rate observed for Crucible attendees could reflect the different focus of the encounters, with Stresa classified as a cultivation encounter, and Crucible as more of a development encounter. The results could also reflect the Crucible availability of seed-funding providing an incentive to develop collaborations and an enabler to deliver projects. Crucibles also organize alumni activities, allowing people the opportunity to meet participants from other cohorts and develop new ideas. The level of interaction, despite no funding or follow-up activities, for the Stresa meeting is also good. However, the issue of incentives was raised:

While Stresa was very interesting and good to meet other researchers across many disciplines (sensitization), it is hard to jointly define a research direction around a very broad theme like water. I would be a supporter for other targeted meetings around somewhat more narrow or focused themes (although not necessarily narrow in disciplinarity!), whereby funding is made available also for follow-up activities in terms of generating research proposals with small ID-teams or the like. Although my work inherently contains working across disciplines, it may need stronger incentives to embark on new challenging collaborations. Nonetheless, it was a nice experience! 
The design of encounters should consider the focus and aims of the encounter and whether seed-funding or other incentives will be important to support follow-on activities. In addition to research outputs, and the career bonus of achieving funding, small funded projects also offer the chance to experience interdisciplinary working, further developing skills that might have been theoretically discussed during a meeting. Previous literature has noted a high level of motivation among early-career researchers in interdisciplinarity ${ }^{1,8,9}$ (one of the responses to the ESF Stresa questionnaire was 'I was hoping the email was about a new Stresa meeting! :)') and it is clear that not only does the organization of encounters offer the opportunity for early-career researchers to engage in such collaborations, but that they fully take advantage of this, developing many new ideas and projects.

Beyond direct new collaborative interdisciplinary projects, encounters offer several other benefits to early-career researchers, including generation of a network of collaborators and peer-support, and development of skills such as confidence and communication as well as broadening perspectives and the opportunity to reflect upon their research direction. Trust and relationship building are key components of successful interdisciplinary research. ${ }^{4,7}$ The data clearly show an increase in confidence among encounter participants in discussing and engaging with others from different disciplines. This indirect benefit of encounter participation should increase the likelihood of future interdisciplinary collaboration since improved communication skills will enable early-career researchers to generate and explore potential collaborative ideas as well as build the strong relationships necessary to successfully deliver the interdisciplinary work. Many participants in both the encounter types surveyed here also report an increased openness towards interdisciplinarity.

One of the challenges raised for early-career researchers is the lack of an extensive network or publication list to leverage interdisciplinary collaborations. ${ }^{6}$ Encounters clearly build strong relationships and allow participants to access researchers from widely different disciplines, helping to overcome this challenge. Crucible alumni activities enable the maintenance and expansion of this network, the advantage of which is evidenced by collaborations across cohorts, and encounters should consider methods of promoting and maintaining links. This is clearly easier within a country, as in the case of Scottish Crucible, compared with the Europe-wide ESF summit.

Finally, this study concentrated on following up the level of interdisciplinary engagement overall and measuring collaboration between encounter participants specifically, and in doing so identified several other benefits of encounter participation. However, one limitation was that any issues and challenges faced by participants in their interdisciplinary journeys were not investigated, and potentially those for whom these experiences were less positive may have been less likely to respond. Further work should concentrate on both the benefits experienced by encounter participants as well as the challenges faced, which could help tailor future encounters to try to equip participants with the skills to solve the potential problems, as well as raise awareness for policy makers and institutions of the current challenges faced by interdisciplinary early-career researchers, which might require adaption of existing funding and reward structures. 


\section{Conclusion}

In summary, this article has evaluated the extent of interdisciplinary collaboration arising from two different types of encounter, targeting early-career researchers, demonstrating that encounters successfully result in many interdisciplinary projects, which often lead to tangible outputs such as publications, conference presentations, further research funding and public engagement. In addition, the article has considered wider, long-term benefits to early-career researchers resulting from encounter participation, with the participants themselves reporting increased confidence, raised profile, improved communication and interdisciplinary working skills along with career development benefits. The findings confirm previous literature that reports high motivation for early-career researchers towards interdisciplinarity and indicates how encounters can assist early-career researchers in overcoming some of the challenges identified in the literature. Therefore, it is concluded that further support should be made available for early-career researchers to access interdisciplinary encounters, as well as to offer seed-funding and follow-up activities. However, little focus was placed on the challenges faced by the early-career researchers during their interdisciplinary journeys and a deeper analysis of potential challenges would be beneficial to maximize the design and delivery of future encounters and to consider how the wider research environment impacts the experience of interdisciplinary earlycareer researchers.

\section{References}

1. H. Bridle, A. Vrieling, M. Cardillo, Y. Araya and L. Hinojosa (2013) Preparing for an interdisciplinary future: a perspective from early-career researchers. Futures, 53, pp. 22-32.

2. A. Barry, G. Born and W. Weszkalnys (2008) Logics of interdisciplinarity. Economy and Society, 37, pp. 20-49.

3. R.R. Brown, A. Deletic and T.H.F. Wong (2015) How to catalyse collaboration. Nature, 525, pp. 315-317.

4. C. Lyall and L.R. Meagher (2012) A Masterclass in interdisciplinarity: research into practice in training the next generation of interdisciplinary researchers. Futures, 44, pp. 608-617.

5. F. Darbellay (2015) Rethinking inter- and transdisciplinarity: undisciplined knowledge and the emergence of a new thought style. Futures, 65, pp. 163-174.

6. H. de Ruiter and K. Gombert (2016) Organising a conference to facilitate interdisciplinary interaction. Education in the North, 23, pp. 148-153.

7. A. Bruce, C. Lyall and L.R. Meagher (2015) Interdisciplinary Research Journeys (London: Bloomsbury Academic).

8. A. Milman, J.M. Marston, S.E. Godsey, J. Bolson, H.P. Jones and S. Weiler (2017) Scholarly motivations to conduct interdisciplinary climate change research. Journal of Environmental Studies and Sciences, 7, pp. 239-250.

9. B. Mallaband, G. Wood, K. Buchanan, S. Staddon, N.M. Mogles and E. GabeThomas (2017) The reality of cross-disciplinary energy research in the United Kingdom: a social science perspective. Energy Research and Social Science, 25, pp. 9-18. 
10. www.open.ac.uk/Arts/pushing-the-boundaries/supporting-interdisciplinarity. pptx.

11. M. Rivera-Ferre, L. Pereira, T. Karpouzoglou, K. Nicholas, S. Onzere, W. Waterlander, F. Mahomoodally, A. Vrieling, F. Babalola, C. Ummenhofer, A. Dogra, A. de Conti, S. Baldermann, C. Evoh and S. Bollmohr (2013) A vision for transdisciplinarity in future earth: perspectives from young researchers. Journal of Agriculture, Food Systems, and Community Development, 3(4), pp. 249-260, doi: 10.5304/jafscd.2013.034.031.

12. R.C. Hedberg II, A. Hesse, D. Baldwin, J. Bernhardt, D.P. Retchless and J.E. Shinn (2017) Preparing geographers for interdisciplinary research: graduate training at the interface of the natural and social sciences. The Professional Geographer, 69, pp. 107-116.

13. S.P. Kemp and P.S. Nurius (2015) Preparing emerging doctoral scholars for transdisciplinary research: a development approach. Journal of Teaching in Social Work, 35, pp. 131-150.

14. J.K. Graybill, S. Dooling, V. Shandas, A. Withey, A. Greve and G.L. Simon (2016) A rough guide to interdisciplinarity: graduate student perspectives. Bioscience, 56, pp. 757-763.

15. H. de Ruiter (2017) Personal communication.

16. C. Lyall, A. Bruce, W. Marsden and L. Meagher (2013) The role of funding agencies in creating interdisciplinary knowledge. Science and Public Policy, 40, pp. $62-71$.

17. G. G. Drake (2003) 'This place gives me space': place and creativity in the creative industries. Geoforum, 34, pp. 511-524.

18. D. Stokols, S. Misra, R.P. Moser, K.L. Hall and B.K. Taylor (2008) The ecology of team science - understanding contextual influences on transdisciplinary collaboration. American Journal of Preventative Medicine, 35, pp. S96-S115.

19. D. Rhoten (2003) A Multi-method Analysis of the Social and Technical Conditions for Interdisciplinary Collaboration (San Francisco, CA: San Francisco, Social Science Research Centre), p. 56.

20. https://issuu.com/cechr/docs/ftf_2016_report.

21. http://www.hutton.ac.uk/blogs/critical-reflection- $\%$ E2\%80\%98octasynthesis $\%$ E2\% $\% 0 \%$ 99-tool-transdisciplinary-thinking.

22. http://www.welshcrucible.org.uk/why-apply/feedback-from-2011/.

\section{About the Author}

Helen Bridle is an Associate Professor at Heriot-Watt University, and her main area of research lies at the interface of engineering and biology. Her specific interests are in the use of microfluidic systems to separate cells, e.g. for the concentration and detection of waterborne pathogens or the isolation and purification of stem cell products. In addition, Dr Bridle is interested in the design of structures and activities for the promotion of interdisciplinarity, especially for early-career researchers. She has participated in both the ESF Junior Summit and Scottish Crucible. Furthermore, public engagement is important to her work, which has been recognized by the receipt of the Royal Society of Edinburgh Innovator's Prize for Public Engagement. 